\title{
PATERNIDADE NA ADOLESCÊNCIA: ASPECTOS TEÓRICOS E EMPÍRICOS
}

\section{ADOLESCENT FATHERHOOD: THEORETICAL AND EMPIRICAL ISSUES}

Daniela C. Levandowski ${ }^{1}$

Cesar A. Piccinini ${ }^{2}$

LEVANDOWSKI, D.C.; PICCININI, C.A. Paternidade na adolescência: aspectos teóricos e empíricas. Rev. Bras. Cresc. Desenv. Hum., São Paulo, 14(1), 49-62, 2004.

Resumo: A paternidade na adolescência constitui-se em uma situação complexa, uma vez que leva o adolescente ao enfrentamento de dois processos impactantes: a adolescência e a paternidade. O objetivo do presente estudo foi revisar os estudos sobre a paternidade na adolescência, enfocando principalmente as suas dimensões sociais, educacionais, económicas, familiares, pessoais e suas conseqüências para a interação pai-bebê. Embora muitos estudos retratem o pai adolescente de forma negativa, pesquisas recentes indicam que muitas das diferenças entre adolescentes e adultos se devem mais a fatores sociais e económicos do que devido à idade do pai. Muitas vezes os adolescentes se envolvem de forma bastante ativa no desempenho do papel paterno, trazendo beneficies diretos para o bebê. É fundamental que se compreenda melhor este fenómeno para que se possa implementar políticas de saúde pública tanto de prevenção como de atendimento a estes adolescentes, protegendo assim não só jovens pais e mães, mas sobretudo 0 bebê.

Palavras-chave: paternidade; adolescência; revisão; literatura.

\section{INTRODUÇÃO}

A paternidade na adolescência, como tema de estudo no meio acadêmico nacional, tem sido um tema ainda pouco examinado. A maior parte dos estudos versam sobre a gestação na adolescência a partir da perspectiva da gestante adolescente. Contudo, dado o expressivo número de casais adolescentes que atualmente passam pela situação inesperada de gestar e cuidar de um bebê, é importante que seja dada uma maior atenção ao futuro pai adolescente. Como contribuição para a área, revisa-se a seguir diversos estudos teóricos e empíricos que se destacam pelas suas contribuições na compreensão deste tema. Inicialmente se busca caracterizar os aspectos biopsicossociais da adolescência. Apresenta-se então os estudos que investigaram a paternidade na adolescência, destacando seus aspectos sociais, edu- cacionais e econômicos, familiares e pessoais. Por fim, examinam-se os aspectos relacionais dos pais adolescentes com a gestante e mãe adolescente, bem como o relacionamento do pai adolescente com seu bebê.

Os autores que se dedicaram ao estudo da adolescência são unânimes em afirmar que esta é uma fase bastante complexa do ciclo vital, pela quantidade e qualidade de transformações biológicas, psicológicas e sociais que o indivíduo experimenta. A adolescência é por isso um evento psicológico e social, além de biológico, que se manifesta diferentemente de acordo com o ambiente social, econômico e cultural do adolescente (KNOBEL,1981).

Nesta perspectiva, os eventos pelos quais o jovem necessita passar mudam de acordo com estes diferentes fatores (MONTMAYOR, 1986; RUSSELL, 1980). Ao examinarem os ritos de

1 Doutora em psicologia, mestre de conferênc ia associada à Universidade de Toulouse le Mirail, perito psicólogo. Placc dc la MaIrie 32160 BEAUMARCHES - França - E-mail: elainef@free.fr 
passagem na adolescência, estes autores relataram a existência de um período de tempo e uma sequência considerados apropriados para que eles aconteçam. Existiria toda uma organizaçao social para apoiar estas passagens, que não estaria presente nos casos em que a ordem de ocorrência ou extensão dos eventos se altera, como por exemplo, quando ocorre uma gestação na adolescência. RUSSELL (1980) ressaltou que a quantidade de estresse de qualquer transição varia com a importância social dos papéis envolvidos, e com o grau no qual esta se dá fora do tempo previsto. Como o papel de pai é fundamental em nossa sociedade, poder-se-ia esperar que a transição precoce para a paternidade seria bastante estressante para os envolvidos, pois os jovens acabariam enfrentando duas crises simultaneamente: a paternidade e a adolescência (NUNES, 1998; ROBINSON, 1988; YOUNG, 1988), sem ainda terem desenvolvido capacidades para lidar com elas (ELSTER \& HENDRICKS, 1986), seja do ponto de vista biológico, psicológico ou social.

Nos primórdios da adolescência, destacamse as mudanças biológicas, associadas à puberdade, caracterizadas pelo aparecimento dos caracteres sexuais secundários, que modificam a aparência e a capacidade reprodutiva do adolescente, bem como sua auto-imagem (BLOS, 1994; OUTEIRAL, 1994; MONTMAYOR, 1986). Já as mudanças cognitivas que também ocorrem na adolescência se traduzem por habilidades de pensamento mais avançadas, que trazem ao adolescente maior aptidão para pensar sobre situações hipotéticas e sobre conceitos abstratos, afetando até mesmo o modo como o adolescente pensa sobre si mesmo, sobre os outros e sobre o mundo (PIAGET, 1976; STEINBERG, 1985). No entanto, ao contrário dos demais estágios de desenvolvimento cognitivo, há pouca consistência quanto à idade na qual a lógica formal se inicia. Isso porque, conforme PIAGET (1976), as operações formais se referem tanto a um estágio de desenvolvimento cognitivo quanto a um estilo de raciocínio. Em uma situação especifica um determinado adolescente poderia ou não recorrer aos recursos da lógica formal, dependendo de diversos fatores, tais como quantidade de experiência prévia com um dado problema, o tipo de problema com o qual está sendo confrontado, seu estado de alerta ou fadiga e sua capacidade intelectual geral. Assim, nem todos os adolescentes contam com este tipo de raciocinio e provavelmente ninguém o adquire completamente durante a adolescência (PIAGET, 1976).

Quanto às mudanças sociais, estas incluem assumir novos papéis sociais e novos direitos, deveres e responsabilidades, tais como licença para dirigir e votar (STEINBERG, 1985). Isto provoca uma redefinição pessoal, com a avaliação de suas habilidades e competências. O jovem pode agora se engajar em outras atividades como casamento, trabalho, o que também altera sua autoimagem e as relações com os outros. Neste contexto, segundo STEINBERG, a consolidação da identidade seria um dos processos mais preeminentes deste periodo. O jovem passa a se preocupar com quem ele realmente é e o que será no futuro, passando por um periodo de experimentação de papéis, na tentativa de encontrar sua verdadeira identidade. Para MONTMAYOR (1986), a família se destaca na formação da identidade, particularmente através da relação pais-filho, sendo o genitor do mesmo sexo um modelo de identificação direta para o adolescente. Outra questão associada à formação da identidade é a aquisição da autonomia, que se caracteriza pela luta do adolescente para ser menos dependente emocionalmente dos pais, e para tomar decisões independentemente, buscando um código de valores próprio (STEINBERG, 1985). Conforme BLOS (1994; 1996), a aquisição da autonomia em relação aos pais seria a tarefa psíquica principal da adolescência. Para YOUNG (1988), no caso da ocorrência da paternidade na adolescência, essa conquista em relação aos próprios pais fica prejudicada, em vista da necessidade de seu apoio para o enfrentamento da nova situação.

Também relacionadas com a consolidação da identidade, destacam-se as manifestações afetivas do adolescente, dentre elas a capacidade de estabelecer uma relação de intimidade (ABERASTURY, 1981). Para a autora, somente quando o adolescente se percebe como um ser único, que necessita de um outro para sua complementação, é que poderá lançar-se a relacionamentos afetivos mais duradouros. Além disto, para MONTMAYOR (1986), a capacidade insuficiente para a intimidade - decorrente de uma identidade precariamente consolidada - seria parcialmente responsável pela insatisfação e discórdia marital encontradas entre casais adolescentes, o que resulta muitas vezes em uma interação de baixa sensibilidade com o bebê.

Por fim, a aquisição de novas capacidades de realização aparece associada a mudanças nos planos educacionais e vocacionais do adolescente, com a tomada de decisões importantes sobre a sua escolarização e carreira (STEINBERG, 1985). Contudo, estas dependem do desempenho escolar do adolescente, da avaliação de suas próprias competências e capacidades, das suas aspirações e expectativas para o futuro e da direção e dos conselhos que recebe de seus pais, professores e amigos. 
Tendo em vista as características de desenvolvimento do adolescente descritas acima, somadas ao advento de experiências sexuais cada vez mais precoces, nota-se que os adolescentes acabam muitas vezes expostos a uma gravidez inesperada. Para KISELICA e PFALLER (1993), isto estaria associado tanto à onipotência característica do adolescente, como à falta de informações sobre o uso de métodos anticoncepcionais adequados. Nos últimos anos tem havido um grande aumento no número de mulheres adolescentes grávidas, tanto em nosso país como no exterior (DIMENSTEIN, 1999; SOARES, 1999). Entre os parceiros destas jovens, tanto antes, como durante e depois da gestação, cada vez mais se encontram adolescentes (HENDRICKS, 1988).

\section{A PATERNIDADE NAADOLESCÊNCIA}

Independente de sua idade, o pai teria sido, historicamente, menos investigado quanto ao seu papel no desenvolvimento do bebê e da criança (ELSTER \& LAMB, 1986). Contudo, nas últimas décadas, houve um aumento de estudos na área, seja no exterior (ANDERSON, 1996; CABRERA, TAMIS-LEMONDA, BRADLEY, HOFFERTH \& LAMB, 2000; COCHRAN, 1997; DALY, 1993; PARKE, 1996), como em nosso contexto (KROB, 1999; MARTINI, 1999; RAMIRES, 1997). Isto pode estar refletindo uma nova concepção social de paternidade, com alguns pais assumindo um papel mais ativo e afetivo na criação de seus filhos, o que tem chamado a atenção dos estudiosos. Contudo, ainda não se percebe uma preocupação tão grande dos autores com a paternidade adolescente, campo em que se constata uma escassez ainda maior de estudos. No exterior, poucos pesquisadores têm se dedicado ao tema, sendo que a maioria dos estudos foi realizada nas décadas de 70 e 80 , sob um enfoque principalmente social e étnico. No Brasil a situação não é diferente, com poucos artigos publicados sobre o assunto (cf. FONSECA,1998).

Embora os pais adolescentes sejam ainda classificados como ausentes, constata-se que este nem sempre é o padrão encontrado (FONSECA, 1998; REDMOND, 1985; TRINDADE \& BRUNS, 1999). Muitos adolescentes têm assumido a paternidade e acompanhado suas namoradas, motivados tanto por questões pessoais como por pressões familiares e/ou sociais. Assim, se antes o próprio adolescente excluía-se da relação da díade mãe-bebê, hoje muitos deles querem se envolver e, por isto, precisam que lhes seja dada a devida atenção e eventual auxílio. Como afirmam ELSTER e LAMB (1986), o pai adolescen- te agora é visto como um componente essencial de um caro problema social.

Além das questões gerais envolvendo a gravidez na adolescência, a paternidade nesta fase de transição tem implicações em diversas dimensões da vida do adolescente. Para fins de exposição, examina-se, a seguir, alguns dos principais aspectos envolvendo a paternidade na adolescência, destacando os aspectos sociais, educacionais e econômicos, familiares e pessoais.

\section{Aspectos Sociais}

No seu estudo com pais adolescentes, FONSECA (1998) deparou-se com um muro de silêncio no trabalho com estes jovens pais, além de bibliografia nacional insuficiente e ausência de dados e de instrumentos de coleta capazes de captar as informações necessárias a uma intervenção. Este silêncio revelava, em sua opinião, uma relação perversa da sociedade adulta para com o jovem, pois ao anular socialmente a paternidade adolescente, acaba-se por legitimar a ausência paterna, dificultando-se ao adolescente pensar, prevenir ou assumir sua condição de pai real ou virtual. Para o autor, o silêncio em relação a este evento deve-se a uma percepção do futuro bebê como "sendo da mãe", e a um reconhecimento do(a) adolescente como sendo principalmente filho(a) e não pai. Assim, FONSECA salienta que, mesmo quando um pai adolescente decide assumir um papel ativo como pai de seu filho, não recebe apoio das instituições sociais (escolares, militares, jurídicas, de saúde, etc.).

De fato, a literatura aponta a falta, em muitos casos, de uma rede de apoio social adequada para auxiliar os pais adolescentes, o que denotaria talvez a existência de preconceitos e barreiras sociais em virtude da paternidade ser considerada um evento adulto (ELSTER \& HENDRICKS, 1986). Nesse sentido, no estudo conduzido por NUNES (1998), os pais adolescentes pensavam ser percebidos pelas outras pessoas como imaturos. A este respeito, ROBINSON (1988) cita alguns estereótipos usados para definir o adolescente pai: o super garanhão, homem vivido, que conhece na prática mais sobre sexo e sexualidade do que os outros adolescentes; o Don Juan, que explora as frágeis adolescentes e tira vantagens delas; o macho, aquele que não tem controle interno e que necessita demais provar sua masculinidade; o fugaz, inconstante, cujos relacionamentos com adolescentes são casuais, com pouco envolvimento emocional; e o pai fantasma, aquele que se ausenta e se afasta do cuidado e educação do filho e também da parceira. Contudo, o autor ressalta que estes estereótipos não podem ser generalizados para todos os adolescentes, pois 
alguns deles envolvem-se fisica e psicologicamente com a mãe da criança e o bebê, o que também é apontado por FONSECA (1997; 1998). Assim, percebe-se a existência de preconceitos de idade, gênero e classe social, pois como afirma FONSECA (1998), há uma idéia dominante da maternidade como fato essencial no destino da mulher, e da não paternidade como destino do homem. Contudo, nem todos os homens e mulheres aceitam passivamente estas prescrições, inclusive os adolescentes.

Um filho na adolescência traz uma mudança de rumo na vida do adolescente, que não sabe lidar com dois novos papéis sociais simultaneamente, o de ser adolescente e ser pai (ELSTER \& HENDRICKS, 1986; NUNES, 1998; ROBIN-SON, 1988). Em um estudo com oito pais adolescentes gaúchos, NUNES (1998) investigou como a paternidade era vivenciada pelos adolescentes, encontrando justamente este paradoxo entre os papéis de pai e de adolescente. Para o autor, o fato de ter filhos, por si só, confronta os pais com a privação da liberdade, porque eles devem, entre outras funções, dar assistência ao recém-nascido. $\mathrm{O}$ adolescente, cuja gravidez não foi planejada, vê uma drástica mudança em sua vida, o que faz com que não saiba lidar bem com os dois papéis contraditórios (fazer festa, farra, ficar com as meninas, ensaiando um comportamento sexual frente ao sexo oposto versus imposição de responsabilidade, privação das festas, saídas noturnas, necessidade de trabalho remunerado). Segundo o autor, o filho na adolescência cria forçosamente mais responsabilidades. $\mathrm{O}$ peso dessas responsabilidades econômicas e psicológicas pode por à prova a personalidade do indivíduo. Infelizmente, a situação retratada pelas pesquisas demonstra a ausência de uma assistência prática útil aos pais adolescentes (ALLEN \& DOHERTY, 1996; HENDRICKS, 1980; 1988). Na verdade, o apoio institucional ou da comunidade serve como um fator de incentivo ou impedimento do envolvimento do pai adolescente com o filho (MARSIGLIO \& COHAN, 1997).

\section{Aspectos Educacionais e Econômicos}

Problemas educacionais e abandono da escola são fatos constantes em caso de uma gestação na adolescência, tanto para a gestante quanto para o futuro pai adolescente. Quanto à educação formal, a paternidade na adolescência está associada a baixos níveis de escolaridade (NOCK, 1998). Estes indicadores de baixa escolaridade independem da etnia do pai adolescente e do fato de viver ou não com a criança (MARSIGLIO, 1986).
O desinteresse pela escola foi também constatado em relação aos adolescentes pais na pesquisa realizada por DEARDEN, HALE e ALVAREZ (1992). A partir de um enfoque retrospectivo nos antecedentes educacionais de homens ingleses que foram pais na adolescência, eles notaram que eles tinham experienciado mais dificuldades acadêmicas do que os não pais, e que estas antecediam a paternidade por mais de uma década. Através de análises estatísticas, os autores verificaram que as variáveis que mediam a falta de interesse dos pais na educação de seus filhos adolescentes estavam fortemente associadas com o risco de paternidade adolescente, assim como a avaliação negativa das habilidades acadêmicas destes meninos feita por seus professores, e o desejo do próprio menino de terminar seus estudos o quanto antes possível. Estudo de FAGOT, PEARS, CAPALDI, CROSBY e LEVE (1998) sobre os preditores de paternidade na adolescência também cita o mau desempenho acadêmico como um forte fator preditor deste evento. $\mathrm{Na}$ pesquisa realizada por STOUTHAMERLOEBER e WEI (1998), investigando a relação entre delinqüência e paternidade adolescente, os autores referem, como possíveis variáveis explanatórias desta relação, estar acima da idade correspondente à série escolar e ter baixo desempenho escolar. Contudo, cabe ressaltar que os resultados dos estudos nem sempre são consistentes. Por exemplo, HENDRICKS (1980) encontrou que pais adolescentes mostravam bom relacionamento com os professores e uma opinião positiva sobre a escola e o estudar e HARRIS (1998) relatou que os adolescentes do seu estudo não deixaram a escola em virtude da paternidade. Independentemente da atitude em relação ao estudar, a freqüência à escola torna-se uma das maiores preocupações dos pais adolescentes, conforme indicaram os resultados encontrados por ELSTER e PANZARINE (1983). Os autores investigaram os estresses de vinte futuros pais adolescentes durante a gestação e o pós-parto, encontrando que na área vocacional-educacional as maiores preocupações referiam-se a como eles dariam suporte financeiro para sua nova família, como manteriam ou adquiririam um emprego e como terminariam a escolarização.

Assim, além dos eventuais problemas escolares, a paternidade adolescente está associada com uma variedade de conseqüências sócio-econômicas negativas. Examinando dados longitudinais, NOCK (1998) mostrou que os pais adolescentes ganham menos, estão menos empregados durante todo o ano e têm taxas de pobreza maiores do que os homens que não tiveram filhos antes do casamento. O estado de pobreza destes ado- 
lescentes é explicado pelo autor em parte pelo casamento ou coabitação, e em parte pela formação de atitudes e crenças inconsistentes com as demandas da força de trabalho. Já o término da escolarização e a conquista de um emprego contribuiriam para o aumento da auto-estima destes adolescentes, bem como para o aumento de sua competência para resolver as tarefas da vida, auxiliando também no desenvolvimento de um sentido de responsabilidade e independência, conforme WESTNEY et al. (1986). Segundo estes autores, somente com esse tipo de assistência os adolescentes conseguiriam realizar seus ideais de paternidade adulta.

\section{Aspectos Familiares}

Quando a gravidez ocorre, os adolescentes expressam grande apreensão em relação às reações de seus pais (FURSTENBERG, 1980). Muitas vezes estes demonstram mais entendimento e apoio do que os jovens esperam, o que os alivia e gratifica. Até as tensões pré-existentes na relação pais-filhos podem, por vezes, se dissolver. Para TRINDADE e BRUNS (1999), os adolescentes e seus pais, ao se depararem com a paternidade, têm seu mundo modificado, pois passam a enfrentar o que até o momento "fingiam" não ver, isto é, a iminência do filho vir a ser pai.

Todos os membros da família são afetados pelo processo de realinhamento promovido pela gravidez na adolescência (FURSTENBER 1980). A partir de uma pesquisa com famílias de gestantes adolescentes, este autor constatou que a gravidez não planejada exigiu uma decisão da família sobre como proceder com a gestação. É necessário decidir as responsabilidades e direitos que serão estendidos ao adolescente e sua família. Para FURSTENBERG, quando o pai adolescente clarifica sua intenção, ele freqüentemente passa a auxiliar no cuidado da criança. De qualquer modo, segundo MARSIGLIO e COHAN (1997), a mãe do bebê e sua família geralmente têm mais poder no que diz respeito ao quanto de contato com o bebê será permitido ao pai e seus parentes.

FURSTENBERG (1980) também postula que a solidez do sistema familiar por vezes bloquearia uma aliança viável da adolescente com o pai do bebê, diminuindo a sua participação no cuidado da criança. Os achados do estudo de CERVERA (1994) com 16 famílias de adolescentes gestantes, utilizando entrevistas, apontam nesta direção, indicando que em várias famílias os adolescentes haviam se afastado do cuidado da criança em função da relação com os familiares da mãe do bebê. Outros estudos também conduzidos com pais adolescentes indicaram que a relação com a mãe adolescente, a família e os amigos, tanto seus como das mães adolescentes, foi considerada obstáculo para seu envolvimento com o bebê, especialmente se estas pessoas eram hostis a eles ou não apoiavam a relação da dupla (ALLEN \& DOHERTY, 1996; DALLAS \& CHEN, 1998).

Ainda em relação à família dos jovens genitores, NUNES ( 1998) encontrou que a pressão maior sobre os adolescentes viria do pai da adolescente, que comumente tem um sentimento de vazio quando outro homem lhe "rouba" e engravida a filha sem permissão. Isso ocasionaria um distanciamento entre o pai da moça e o adolescente, em um momento em que seria inenos angustiante para ambos se existisse um diálogo e uma troca de experiências paternas.

Apesar destas dificuldades, cabe ressaltar que muitas vezes os familiares assumem uin papel bastante grande no cuidado da criança, permitindo aos adolescentes que lidem de forma adequada com os estresses de uma parental idade precoce (FURSTENBERG, 1980). Contudo, o cuidado precoce de uma criança pode tanto trazer benefícios para toda a família como também prejuízos, dependendo do sentido atribuído ao evento. Para FURSTENBERG, existem diferenças no grau em que as diversas famílias permitiriam um crescimento no desempenho do papel materno e paterno pelos jovens. Na verdade, a família já aparece como fator protetor contra a ocorrência da gestação na adolescência, pois, dependendo de suas atitudes, estimula o jovem a manter relações sexuais seguras (JORGENSEN, 1993).

Ainda quanto à família de adolescentes genitores, CHRISTMON (1990a) encontrou que a relação e atitudes do pai adolescente em relação à sua família de origem influenciavam no seu desejo de se envolver com o bebê. DALLAS e CHEN (1998) também assinalaram outros fatores que influenciariam estes adolescentes, como a participação de seu próprio pai biológico em sua vida, a quantidade de contato com ele, sentimentos de abandono e crenças sobre a singularidade do papel paterno.

A literatura também sugere um padrão de relação familiar característico envolvendo pais adolescentes. Estes teriam uma relação bastante próxima com a própria mãe, enquanto que seu pai seria ausente (emocional ou fisicamente; CHRISTMON, 1990b; ELSTERHEN \& ENDRICKS, 1986; TRINDADE \& BRUNS, 1998). Esta situação poderia influenciar negativamente o adolescente, por receber uma mensagem de que seu futuro papel não significa envolvimento com o bebê, já que esta seria uma tarefa feminina. Existem evidências de que os pais tanto servem como um modelo direto para o adoles- 
cente, quanto indireto, ainda mais em virtude do questionamento da estrutura familiar, próprio da adolescência (TRINDADE \& BRUNS, 1999).

\section{Aspectos Pessoais}

Um dos aspectos investigados em relação ao pai adolescente é a prontidão para a paternidade. WESTNEY e colaboradores (1986), numa investigação que envolveu adolescentes que se tornaram pais, encontraram que dos 28 pais adolescentes do seu estudo, 21 haviam projetado se tornar pais a partir dos 20 anos, ou seja, depois da idade em que isto efetivamente aconteceu. $\mathrm{Na}$ pesquisa de ALLEN e DOHERTY (1996), muitos dos pais adolescentes também perceberam-se como tendo sido pais muito precocemente, sendo que alguns desejavam adiar o evento. $\mathrm{O}$ mesino foi encontrado por NUNES (1998), pois os pais adolescentes investigados, de modo geral, não se encontravam preparados psiquicamente para realizar todos os ajustes necessários ao desempenho do novo papel. De fato, conforme BELSKY e MILLER (1986), quando coinparados aos pais adultos, os adolescentes não apresentariam uma prontidão psicológica para a paternidade, em virtude de serem menos racionais em suas decisões, menos capazes de fazer julgamentos morais e cognitivos e terem menos informações sobre o desenvolvimento infantil. Para COCHRAN (1997), como muitos pais adolescentes não planejaram a gestação, não se encontram preparados para assumir este novo papel, até mesmo porque suas expectativas sobre sua habilidade para cumprir com suas obrigações paternas são muitas vezes irreais.

Outra razão da falta/ausência de prontidão dos adolescentes em relação à paternidade seria a ambivalência provocada pelo desejo por autonomia, típico da adolescência, e a nova dependência dos pais provocada pela situação de cuidar de um bebê (TETI \& LAMB, 1986). Além disso, a consolidação da identidade também dificultaria a prontidão do adolescente para a paternidade, pois um pai adolescente com uma idenlidade difusa pode encontrar dificuldades em ser pai e marido efetivo (MONTMAYOR, 1986). Ainda a falta de um senso claro de identidade pode fazer, segundo o autor, com que o adolescente passe a competir com sua criança pela atenção da parceira, e se sinta ameaçado e com ciúmes do interesse que ela demonstra pelo bebê.

A falta de prontidão poderia estar refletida também na reação inicial dos adolescentes à notícia da gravidez, em geral negativa ou ambivalente, envolvendo tristeza, choque, surpresa, medo (DALLAS \& CHEN, 1998; WESTNEY et al., 1986). Para TRINDADE e BRUNS (1999), estes tipos de respostas dos pais adolescentes refletiriam sua imediatez e envolvimento como agora, que não engloba uma reflexão sobre a possibilidade de uma gravidez. O susto inicial revelaria, então, a idéia de que estes adolescentes não estão na idade certa para ser pai, ficando perplexos quando isso se mostra como realidade.

Um outro aspecto bastante mencionado nos estudos sobre paternidade na adolescência é o aumento de responsabilidade (ALLEN \& DOHERTY, 1996). Estes autores constataram que muitos pais adolescentes pareciam sobrecarregados pelo grande número de obrigações paternas. Também no estudo realizado por HARRIS (1998), os adolescentes enfatizaram o aumento da responsabilidade e a redução da liberdade como aspectos negativos de tornarse pai. Além disso, DAL-LAS e CHEN (1998) encontraram adolescentes confusos sobre o que esperar da paternidade, sobre seu papel durante a gestação e sobre como reagir quanto às mudanças do corpo, do humor e dos comportamentos da adolescente. Com base nos discursos de adolescentes pais, TRINDADE e BRUNS (1999) afirmaram que a paternidade é uma experiência dolorosa, que arranca subitamente o adolescente de seu cotidiano comumente marcado pela falta de responsabilidade e de envolvimento em seus projetos. A gravidez exige uma súbita reformulação dos seus planos e a ainbigüidade envolvendo estas mudanças implica numa falta de engajamento com a paternidade, evidenciada na dúvida quanto ao desejo de ser pai. Conforme as autoras, muitas vezes esta ambigüidade é reforçada pela mídia ou pelo discurso de outras pessoas, tais como colegas ou familiares.

Obviainente muitas das preocupações envolvendo a paternidade, tais como prover suporte material e assistência aos problemas da criança, tendem a ser comuns tanto para adultos como para adolescentes, embora estes últimos tenham menos recursos (DALLAS \& CHEN, 1998). Por exemplo, já no período da gravidez os adolescentes vivenciariam maiores estresses do que os futuros pais adultos (ELSTER \& PANZARINE, 1983), com destaque para as preocupações vocacionais-educacionais, preocupações em relação à saúde da mãe e do bebê, quanto ao parto e nascimento, preocupações sobre sua atuação como pai, incluindo questões de disciplina e cuidados, problemas nas relações do casal, com os amigos, os próprios pais, sentimentos de alienação religiosa, ciúme da atenção que o bebê estava recebendo, inveja da liberdade de seus pares e preocupações pela saúde de seus próprios pais devido à gestação. Os achados de ELSTER e PANZARINE confirmam a idéia de um padrão reproduzível nos tipos de estressores que afetam estes 
pais, independentemente de sua raça, estado civil ou nivel sócio-econômico. Os autores declararam ainda que o modo como os futuros pais gerenciarão a crise simultânea da gestação, da futura paternidade e do casamento influenciará em seu comportamento e no de sua parceira.

Ainda em relação aos aspectos pessoais envolvendo o pai adolescente, ROBINSON e FRANK (1994) estudaram a auto-estima de 313 jovens de ambos os sexos e etnias diversas, e sua relação com seu comportamento sexual. As análises revelaram diferenças significativas apenas entre os jovens que se tornaram pais, pois estes apresentaram um nível menor de auto-estima do que os que não se tornaram pais na adolescência. Contudo, é importante assinalar que os resultados apresentados na literatura não são consistentes em relação à auto-estima do pai adolescente. A revisão de Allen e DOHERTY (1996) indicou o oposto, mostrando que os pais adolescentes encontravam-se com a auto-estima elevada por tornarem-se pais.

Um outro aspecto examinado na literatura é a relação entre a paternidade adolescente e a delinqüência. Com base em dados quantitativos de um estudo longitudinal, STOUTHAMERLOEBER e WEI (1998) investigaram adolescentes norte-americanos pais e não pais, assim como seus genitores e professores. Os resultados revelaram que os fatores relacionados com a paternidade adolescente se constituíram em um subconjunto de fatores relacionados com a delinqüência. Os futuros pais adolescentes apresentavam uma probabilidade duas vezes maior para a delinqüência do que nos não pais durante os quatro anos de observação, indicando que esta tendência não declinava com a paternidade. Os pais adolescentes tenderam a cometer vários atos delinqüentes no ano em que se tornaram pais e no ano seguinte, em geral envolvendo-se em roubo e uso de drogas e bebidas. Eles tinham também uma tendência maior a ter uma ação judicial contra eles do que os não pais.

O estudo realizado por FAGOT e colaboradores (1998) também apontou para achados semelhantes. Através de um estudo comparativo envolvendo 35 adolescentes norteamericanos pais e um grupo controle de adolescentes não pais, os autores investigaram os preditores da paternidade adolescente e a qualidade de vida de suas crianças em termos de saúde e tipo de supervisão parental recebida. Entre os preditores mais importantes para a paternidade na adolescência destacava-se o contexto de risco em que viviam (baixo status sócio-econômico, comportamento parental antisocial), pobre disciplina parental, engajamento em um grupo de iguais desviante, falhas acadêmicas e comportamento anti-social. Tais fatores são comumente associados com o desenvolvimento do comportamento anti-social. Os dados também mostraram que os pais jovens tinham sido presos mais vezes do que o restante da amostra. Além disso, usavam mais drogas e cigarro e completavam o segundo grau menos freqüentemente. No entanto, as impressões clínicas do estudo sugeriram que muitos pais pareciam aceitar a paternidade desejosamente, como algo que melhoraria suas vidas e que os faria funcionar completamente como adultos. Entretanto, para os autores, esta impressão poderia também indicar um pensamento imaturo dos adolescentes, relacionado com falhas no seu desenvolvimento.

A partir do exposto acima, têm-se uma visão das possíveis conseqüências da paternidade adolescente, em várias dimensões da vida do adolescente, quando foram destacados os aspectos educacionais, econômicos, familiares e pessoais. Como pode-se constatar, são inúmeras as implicações deste evento na vida do adolescente e obviamente o apoio social disponível pode-se constituir num fator de proteção. Caso isto não ocorra, a transição para a paternidade do adolescente será dificultada e trará conseqüências também para a relação com a gestante e mãe adolescente, bem como para a própria relação pai-bebê, como será visto abaixo.

\section{Aspectos Relacionais dos Pais Adolescentes com a Gestante/mãe Adolescente}

Muito do que se conhece sobre as atitudes de pais adolescentes não casados em relação à paternidade e sua relação com as mães de sua criança se deve a depoimentos das mães adolescentes. Há uma escassez de registros sobre as percepções dos próprios pais adolescentes sobre esta relação.

A literatura revela a existência de duas posições a respeito das conseqüências da gravidez na vida conjugal de casais adolescentes, uma positiva e outra negativa. De um lado, a parentalidade uniria o casal, até mesmo pela decisão de morarem juntos, promovendo um crescimento da dupla e uma relação afetiva positiva (DALLAS \& CHEN, 1998; HENDRICKS, 1988; NUNES, 1998; TRINDADE \& BRUNS, 1999; WESTNEY et al., 1986). HENDRICKS e MONTGOMERY (1983) também relataram que muitos dos pais adolescentes que examinaram, consideravam sua relação com a mãe do bebê como sendo de amor, tanto antes como após o parto. Além disso, no estudo de DALLAS e CHEN (1998), os participantes viam esta relação como importante para o bem-estar da criança e eles esperavam continuar seu relacionamento com a mãe da criança após o 
nascimento do bebé, embora não necessariamente através de um casamento. Conforme estudo realizado por HENDRICKS (1988), esses aspectos positivos no relacionamento do casal adolescente também parecem não variar entre diferentes grupos étnicos.

Contudo, a parentalidade pode ter também efeitos negativos sobre a relação conjugal, especialmente com o nascimento do filho e a decisão de morar junto minando o estado de enamoramento anterior ( I RINDADE \& BRUNS, 1999). Isto porque a nova rotina tende a mudar a relação, e o filho exige uma exclusividade que é incompatível com a estrutura instável da paixão, o que exige dos adolescentes uma reformulação na maneira de viver com a parceira. Nesse sentido, muitos autores enfatizaram que duplas que casam na adolescência experimentariam mais problemas maritais e taxas de divórcio mais altas (ATWATER, 1988; ELSTER \& PANZARINE, 1983; STEINBERG, 1985). Por exemplo, a taxa de divórcio é três vezes maior para homens jovens do que para homens que casam aos 30 anos e quatro vezes maior para jovens mulheres quando comparadas com mulheres adultas (STEINBERG, 1985). Dados mais recentes contrapõem-se a esta tendência e revelam que adolescentes possuíam níveis de satisfação marital e instabilidade nas relações pessoais semelhantes aos de homens adultos (HEATH \& MCKENRY, 1993). Além disso, a satisfação com o papel de pai do jovem era maior do que a do grupo de homens adultos. Contudo, um problema deste estudo é que os pesquisadores não investigaram se esses achados ocorreriam pelo fato desses pais não assumirem responsabilidades em relação ao cuidado da criança, tendo assim uma visão mais positiva do papel paterno.

É plausível se pensar que a maior taxa de instabilidade marital entre casais adolescentes se deve a características negativas que estão associadas com altas taxas de divórcio também em outras idades, como por exemplo: casar por causa de uma gestação, viver sob estresse econômico, ter menor nível educacional e perspectivas de trabalho mais limitadas (STEINBERG, 1985). Em função destes fatores, a vida conjugal já seria iniciada com problemas de difícil solução que não contribuem para o sucesso do casamento.

Quando a relação com a mãe do bebéê era conflituosa, os problemas mais citados pelos pais adolescentes do estudo de HENDRICKS e MONTGOMERY (1983) foram: a adolescente não o deixava ver o bebê, faltava entendimento e comunicação, ver outros rapazes aproximandose da adolescente, discussões sobre capacidades e habilidades do bebê, não passar tempo suficiente com a adolescente, problemas com a mãe dela e falta de dinheiro. De fato, a relação com a mãe da criança, quando positiva, se constitui em um fator promotor do envolvimento e participação dos pais, pois afeta tanto a quantidade como a qualidade das interações com a criança (ALLEN \& DOHERTY, 1996). Contudo, quando a relação não é boa, os participantes referiram ver menos freqüentemente a criança e também pareceram mais reticentes sobre a natureza específica de suas interações com sua criança.

\section{A interação pai-adolescente-bebê}

Como já foi visto acima, em virtude das dificuldades geradas pela paternidade na adolescência, muitos autores sugerem que os adolescentes não desejam se envolver com o bebê e assumir as responsabilidades da paternidade (AMAZARRAY, MACHADO, OLIVEIRA \& GOMES, 1998; DENNISON \& COLEMAN, 1998; PARKE, POWER \& FISHER, 1980). No entanto, a idéia do não envolvimento é contraposta em outras pesquisas que indicam que os pais adolescentes demonstram um desejo de participar do cuidado da criança e permanecem em contato com o bebê após seu nascimento (ALLEN \& DOHERTY, 1996; CHRISTMON, 1990B; COCHRAN, 1997; DALLAS \& CHEN, 1998; DENNISON \& COLEMAN, 1998; NUNES, 1998; ROBINSON, 1988; WESTNEY et al., 1986).

De fato, conforme CHRISTMON (1990b), o falo de que os pais adolescentes têm sido ativos na vida de suas crianças tem sido largamente ignorado. PARKE, POWER e FISHER (1980) comentam até que o fato dos pais adolescentes terem pouco contato com seu bebê é um preconceito, uma concepção errônea veiculada socialmente. Na verdade, a partir de uma revisão de literatura, COLEY e CHASE-LANSDALE (1998) encontraram que, apesar das baixas taxas de casamento e alta incidência de divórcio entre casais adolescentes, pelo menos $50 \%$ dos pais adolescentes vivem com sua criança depois do nascimento, embora esta situação não dure muito e dependa de inúmeros fatores, alguns dos quais assinalados acima. Quando o convívio não ocorre, muitos pais adolescentes continuam vendo suas crianças regularmente, ao menos durante os primeiros anos. Segundo DENNISON e COLEMAN (1998), o que parece acontecer é que muitos pais adolescentes querem se envolver, e quando não o fazem seria por considerarem as demandas e responsabilidades da paternidade muito grandes frente às suas habilidades pessoais.

Assim, vê-se que os pais adolescentes podem se deparar com barreiras de natureza variada, que lhes dificultam o envolvimento com o bebê 
e o desempenho do papel paterno. Uma dessas barreiras também poderia ser o papel sexual ainda em construção pelos jovens pais (CHRISTMON, 1990a; TETI \& LAMB, 1986). Este fato os faria evitar quaisquer comportamentos de cuidado, que seriam estereotipadamente femininos. Após a resolução desta questão, os homens poderiam ampliar suas concepções de papel sexual masculino e sentir-se menos ameaçados pela expressão deste tipo de comportamentos (TETI \& LAMB, 1986).

Porém, em várias pesquisas os pais adolescentes também referiram um envolvimento significativo na vida da criança, seja através de contribuição financeira ou outras formas alternativas de cuidado (ALLEN \& DOHERTY, 1996; DALLAS \& CHEN, 1998; TRINDADE \& BRUNS, 1 999). Assim, mesmo citando várias barreiras em relação à paternidade, os pais adolescentes referiram ter um papel importante na vida de sua criança de forma global, sendo capazes de vencer os obstáculos encontrados e se tornarem pais competentes e cuidadores (COCHRAN, 1997; MARSIGLIO \& COHAN, 1997; ROBINSON, 1988; YOUNG, 1988).

Tratando mais especificamente da interação pai-bebê, de acordo com LAMB e ELSTER (1986), a habilidade de proporcionar uma interação parental de alta qualidade, antes considerada como uma característica pessoal do genitor, hoje é vista como sendo também influenciada por fatores ambientais e da criança. De qualquer modo, o primeiro fator citado por estes autores seria o desenvolvimento cognitivo do adolescente, que estaria adquirindo o pensamento lógico e abstraio, como já citado anteriormente. Vários autores (MARSIGLIO \& COHAN, 1997; MCARNEY, LAWRENCE, ATEN \& IKER, 1984; SADLER \& CATRONE, 1983;YOUNG,1988) consideram que essa imaturidade cognitiva, aliada às tarefas da adolescência, criaria um egocentrismo, que impediria que as necessidades do bebê fossem avaliadas corretamente e como mais urgentes do que as do próprio jovem.

Como segundo fator apareceria o desconhecimento dos estágios de desenvolvimento do bebê, que poderia alterar as atitudes em relação à criação e cuidado do bebê através de expectativas errôneas em relação às suas capacidades (LAMB \& ELSTER, 1986). Por um lado, a falta de conhecimento poderia levar a uma subestimação das capacidades da criança, considerando-a apenas uma portadora de necessidades físicas, com limitada capacidade mental, ou então poderia levar a uma superestimação de suas capacidades (ALLEN \& DOHERTY, 1996; HARRIS, 1998; LAMB \& ELSTER, 1986;
MARSIGLIO \& COHAN, 1997). Dessa forma, o conhecimento escasso impediria uma interpretação correta das necessidades do bebê, e por conseguinte, uma resposta adequada a elas. Além disso, as expectativas irreais sobre o bebê poderiam levar a atitudes impacientes e intolerantes que freqüentemente resultariam em disciplinamento físico punitivo (REIS \& HERZ, 1987; ROBINSON, 1988; ROBINSON \& BARRET, 1987). De fato, na literatura encontram-se alguns estudos sugerindo que os pais adolescentes estariam mais propensos a abusar e maltratrar seus filhos (ex.: FAGOT et al., 1998). Entre as causas citadas por JORGENSEN (1993) para este comportamento estariam: as expectativas irreais sobre $o$ comportamento e o desenvolvimento da criança, estresses relativos aos familiares, cônjuges e emprego, frustração cansada por não atingir seus objetivos educacionais e ocupacionais, insegurança econômica e baixa renda e isolamento dos amigos como resultado da gravidez. Contudo, as expectativas de alta incidência de maus tratos entre pais adolescentes nem sempre são confirmadas (BOLTON \& BELSKY, 1986). Isto porque o risco decorre também do número e grau dos estresses e da capacidade do adolescente de lidar com estas situações. Contudo, em virtude dos escassos conhecimentos sobre a relação entre pais adolescentes e seus bebes, muitas vezes são aplicados a estes casos conhecimentos adquiridos entre pais adultos, que não repetem necessariamente o contexto envolvendo os adolescentes. De qualquer modo, segundo BOLTON e BELSKY (1986), os pais adolescentes estariam em posição de maior risco para abuso e maus tratos do que as mães adolescentes, em virtude das pressões que enfrentam serem mais fortes do que as enfrentadas por elas.

As causas para o desconhecimento dos adolescentes sobre o desenvolvimento infantil seriam a menor escolaridade dos jovens e/ou a menor quantidade de contato e experiências com crianças (DENNISON \& COLEMAN, 1998; LAMB \& ELSTER, 1986; MARSIGLIO \& COHAN, 1997; YOUNG, 1988). Os achados do estudo de WESTNEY, COLE e MUNFORD (1988), confirmam esta idéia, pois quanto mais o pai adolescente tinha conhecimento do bebê, mais esperava oferecer apoio para a gestante e o bebê.

$\mathrm{O}$ terceiro fator que influenciaria a qualidade da interação mãe-bebê seriam as características do próprio bebê, destacando-se as psicológicas e comportamentais (LAMB \& ELSTER, 1986). Alguns bebês são claramente mais sociáveis que outros, empregando mais formas de estabelecer contato com os pais. Quando as interações são mutuamente satisfatórias, os pais mais 
provavelmente desenvolvem um sentimento de auto-confiança e efetividade que por consequência melhoraria a qualidade da interação. Infelizmente, os achados de vários estudos concluem que as mães adolescentes em geral percebem seu bebê como sendo de temperamento mais difícil (JORGENSEN, 1993; MARSIGLIO \& COHAN, 1997). Embora estes estudos não falaram do pai adolescente, é plausível supor que eles também tenham uma impressão semelhante sobre o seu bebê. Já em relação ao gênero, os pais adolescentes poderiam preferir o sexo masculino, até mesmo pela etapa de desenvolvimento da identidade sexual em que se encontram (MARSIGLIO \& COHAN, 1997). Além disso, o tipo de relacionamento que os pais adolescentes estabelecem com a criança é influenciado pelo fato da gravidez não ser desejada ou antecipada nesta idade. Contudo, isto varia em função dos recursos psicológicos e econômicos, bem como do apoio social recebido.

A qualidade da interação também seria afetada pelo estresse parental, que diminuiria a sensibilidade do genitor ao bebê (CHRISTMON, 1990a; LAMB \& ELSTER, 1986). Como mencionado anteriormente, os adolescentes poderiam enfrentar mais estresses em virtude da ocorrência da gestação fora do tempo previsto socialmente, somado ao fato de terem menos recursos pessoais para lidar com o estresse (LAMB \& ELSTER, 1986; RUSSEL, 1980).

O último fator citado por LAMB e ELSTER como influenciando o comportamento parental seria o apoio social, que pode se dar na forma de oferecimento de modelos, reforçamento social, assistência, estimulação social e apoio emocional. A sensibilidade parental poderia ser afetada pela rede de apoio social através da diminuição do estresse, do aumento do conhecimento sobre desenvolvimento infantil, da promoção da autoestima e da efetividade percebidas e/ou do fornecimento de uma ajuda prática. $\mathrm{O}$ apoio mais importante parece ser o emocional, principalmente quando proveniente da família de origem. Além disso, viver na casa dos próprios pais após o nascimento do bebê também ajudaria a obter melhores resultados profissionais e educacionais.

Apesar de todos estes fatores que podem influir negativamente na interação pai adolescente-bebê, LAMB e ELSTER (1985) não encontraram muitas diferenças significativas em função da idade dos pais (adolescentes e adultos) nos comportamentos observados na interação com o bebê aos seis meses de vida. Também não foram encontradas diferenças significativas quanto ao estresse referido pelos pais, o apoio social recebido e a qualidade diádica. Na verdade, foram encontradas apenas três diferenças significativas entre as medidas observacionais. Os pais adultos e adolescentes de menor idade foram significativamente mais responsivos aos bebês do que os pais adultos jovens. Os pais adultos também se engajaram mais em estimular o bebê do que os pais adolescentes de menor idade e os adultos jovens. Além disso, tenderam a partilhar mais prazer com as mães do que os outros grupos. No entanto, de forma geral, a idade do pai contribuiu para poucas diferenças nas interações mãe-bebê, pai-bebê e mãe-pai. Para estes autores, as adolescentes e seus parceiros se assemelham muito aos pais adultos.

Os resultados do estudo recente de LEVANDOWSKI e PICCININI (2002) apontam na mesma direção, ao examinar a interação pai-bebê em nove pais adolescentes e onze adultos aos três meses de vida do bebê. Com base numa situação de interação livre realizada na residência das famílias, não houve diferença significativa quanto à responsividade dos pais adolescentes quando comparados aos adultos. Em relação à responsividade, a ausência de diferenças entre os dois grupos de pais endossa os achados de alguns estudos que enfatizam que a interação pai adolescentebebê não diferiria tanto da interação pai adultobebê (BOLTON \& BELSKY, 1986; COCHRAN,1997; MARSIGLIO \& COHAN, 1997; NAKASHIMA \& CAMP, 1984).

Na verdade, a idade parental parece ser um determinante muito menos importante para a qualidade do comportamento parental do que uma variedade de fatores sócio-econômicos e variáveis de personalidade que estão freqüenteinente correlacionadas com a idade parental, obscurecendo assim as relações envolvidas. Portanto, mesmo que vários fatores possam influenciar negativamente a qualidade e quantidade das interações paternas, os pais adolescentes tendem a oferecer beneficios diretos e indiretos para a criança (ALLEN \& DOHERTY, 1996). No estudo de CABRERA e colaboradores (2000), entre os benefícios diretos estaria o auxílio com a alimentação e roupa e outras necessidades materiais da criança, bem como a disponibilidade emocional. Já os beneficies indiretos seriam as diferentes formas de apoio para a mãe adolescente, em especial o emocional (ALLEN \& DOHERTY, 1996), isso porque a qualidade da relação entre pai e mãe em vários momentos afeta as atitudes e comportamentos matemos, o que por sua vez afeta o desenvolvimento social e cognitivo da criança. Juntos estes estudos revelam que, apesar de estereótipos populares retratarem os pais adolescentes como irresponsáveis e exploradores, as poucas pesquisas existentes sobre a interação destes pais com o bebê mostram semelhanças com o pa- 
drão encontrado entre pais adultos e seus bebês. De qualquer modo, em função da maior variabilidade de situações envolvendo os adolescentes do que os adultos, é plausível se supor que pelo menos alguns adolescentes se enquadrem dentro dos estereótipos existentes que os desqualificam como pais, pelo menos nas situações em que eles padecem de grande carência de apoio familiar e social.

\section{CONSIDERAÇÕES FINAIS}

A revisão da literatura sobre a patemidade adolescente indica um reduzido número de estudos sobre este tema, tanto no exterior como em nosso meio. Enquanto existe um extenso número de publicações sobre a maternidade na adolescência, pouca atenção tem sido dada ao pai adolescente.

É também evidente na literatura a presença de estudos que tendem a retratar negativamente o pai adolescente, sem assinalar que as deficiências que eles possam estar apresentando podem ocorrer também com pais adultos, uma vez que eles não tenham o devido apoio familiar, social e financeiro. Obviamente, a situação de adolescência cria uma situação mais complexa para a patemidade. Eles vivenciariam maiores estresses, estariam menos aptos a serem pais em função do seu desenvolvimento cognitivo e afetivo, teriam uma interação menos responsiva com o bebê e o relacionamento do casal não sena tão bem-sucedido. Estas idéias, no entanto, parecem estar sendo contrapostas por pesquisas mais recentes, que não encontram muitas diferenças entre pais adolescentes e adultos, alegando que estas se devem principalmente a fatores sociais e econômicos, e não pessoais.

Percebe-se também que a patemidade na adolescência não pode mais ser considerada como fato irrelevante, continuando esquecido e desconhecido em nosso meio. Ao contrário, precisa-se conhecer melhor estes futuros pais para que se possa ajudá-los em suas necessidades, a fim de que possam desempenhar a patemidade de forma mais efetiva em uma idade tão precoce. Novas investigações se fazem necessárias, principalmente no que diz respeito à vivência da patemidade e à interação do pai adolescente com seu bebê. Em relação a este último assunto, chama atenção o fato de que a observação direta das díades e a comparação com pais adultos não têm sido utilizadas na literatura revisada. Muitas vezes o entendimento sobre a patemidade adolescente ainda é derivado de estudos baseados nas impressões das mães adolescentes ou então a partir de estudos com pais adultos. Somam-se a estes estudos feitos com outros grupos os estereótipos sociais existentes sobre o adolescente e acaba-se sem uma compreensão adequada sobre a patemidade adolescente tanto nos seus aspectos objetivos e especialmente nos subjetivos. Com este quadro em mente, fica difícil se tirar conclusões sobre os riscos de ajustamento existentes nas situações envolvendo a patennidade adolescente, ou ainda o quanto condições de desenvolvimento inadequadas levariam a uma maior incidência de patemidade adolescente.

Estudos epidemiológicos serão fundamentais para se esclarecer muitas destas questões sobre a patemidade adolescente, tanto quanto aos eventuais fatores preditivos, como em relação aos fatores de risco e protetores durante a transição do adolescente para paternidade. A prevalência de gravidez na adolescência está aumentado, tanto no extenor como ern nosso país, e atualmente milhões de jovens precisariam de assistência emocional, social e financeira para suportarem esta situação. Assim, é fudamental que se compreenda melhor este fenômeno para que se possa implementar políticas de saúde pública tanto de prevenção como de atendimento a estes adolescentes. Com isto se estará protegendo não só novos adolescentes pais e mães, mas sobretudo o bebê que vai nascer, que precisa de muitos cuidados e cannho, para que não venha a repetir o que aconteceu com seus jovens pais.

\begin{abstract}
Adolescent fatherhood is a complex situation, as it requires that the adolescent copes with two influential processes: adolescence and fatherhood. The aim of this study was to revise the studies on adolescent fatherhood, focusing especially on their social, educational, economic, family and personal dimensions and their consequences for father-baby interaction. Although many studies portray the adolescent father in a negative way, recent studies seem to indicate that the differences between adolescents and adults are due to social and economic factors rather than to the father's age. Besides, the adolescents seem to be actively involved in the paternal role, which brings direct and indirect benefits to the baby. It is important that this phenomenon is better understood so that public health policies of both prevention and assistance to these adolescents may be implemented, in order to protect not only the adolescent mothers and fathers, but especially the baby.
\end{abstract}

Key-words: adolescent; fatherhood; literature; review. 


\section{REFERÊNCIAS}

Aberastury A. O adolescente e a liberdade. In: Aberastury A, Knobel M, organizadores. Adolescência normal: um enfoque psicanalítico. $\wedge \mathrm{I} \wedge \mathbf{O}^{\wedge}$ a. ed. Porto Alegre: Artes Médicas, 1981. p.13-23.

Allen WD, Doherty WJ. The responsibilities of fatherhood as perceived by African American teenage fathers. Families in Society, 1996, 77(3): 142-55.

Amazarray MR, Machado OS, Oliveira VZ, Gomes WB. A experiência de assumir a gestação na adolescência: um estudo fenomenológico. Psicol Reflex Crit, 1998, 11(3): 431-40.

Anderson AM. Factors influencing the fatherinfant relationship. J Fam Nurs, 1996, 2(3): 306-24.

Atwater E. Adolescence. $2^{\mathrm{a}}$ ed. New Jersey: Prentice Hall, 1988.

Belsky J, Miller BC. Adolescent fatherhood in the context of the transition to parenthood. In: Elster AB, Lamb ME, orgs. Adolescent fatherhood. Hillsdale (New Jersey): Lawrence Erlbaum, 1986. p.107-21.

Blos P. Adolescência: uma interpretaçào psicanalítica. São Paulo: Martins Fontes, 1994.

Blos P. Transição adolescente: questões desenvolvimentais. Porto Alegre: Artes Médicas, 1996.

Bolton FG, Belsky J. The adolescent father and child maltreatment. Em AB Elster, ME Lamb (org.), Adolescent fatherhood (pp. 123-140). Hillsdale, New Jersey: Lawrence Erlbaum, 1986.

Cabrera NJ, Tamis-Le Monda CS, Bradley RH, Hofferth S, Lamb ME (2000). Fatherhood in the twentyfirst century. ChildDev., 71(1), 127136.

Cervera N. (1994). Family change during an unwed teenage pregnancy. Journal of Youth and Adolescence, 23(1), 119- 140.

Christmon K. (1990a). Parental responsibility ans selfimage of African American teenage fathers. Families in Society, 71(9), 563-567.

Christmon K. (1990b). Parental responsibility of African American unwed adolescent fathers. Adolescence, XXV (99), 645-653.

Cochran DL. (1997). African american fathers: A decade review of the literature. Families in Society, 343-351.

Coley RL., Chase-Lansdale PL. (1998). Adolescent pregnancy and parenthood: Recent evidence and future directions. Am. Psychol., 53(2), 152-166.

Dallas CM, Chen SC. (1998). Experiences of African American adolescent fathers. West. J. Nurs. Res., 20(2), 210-222.
Daly K (1993). Reshaping fatherhood: Finding the models. Journal of Family Issues^714(4), 510-530.

Dearden K, Hale C, Alvarez J (1992). The educational antecedents of teen fatherhood. $\mathrm{Br}$. J. Educ. Psychol., 62(1), 139-147.

Dennison C, Coleman J (1998). Teenage motherhood: Experiences and relationships. In: S. Clement (Org.). Psychological perspectives on pregnancy and childbearing (pp. 245-263). London: Churchill Livingstone.

Dimenstein G (1999). Desinformação provoca riscos sexuais. Jornal Folha de São Paulo, 15 de maio de 1999, Seção Cotidiano, p. 05.

ElsterAB, Panzarine S (1983) Teenage fathers: Stresses during gestation and early parenthood. Clin. Pediatr., 22(10), 700-703.

Elster AB, Hendricks L (1986). Stresses and coping strategies of adolescent fathers. Em A. B. Elster, M. E. Lamb (org.). Adolescent fatherhood (pp. 58-65). Hillsdale, New Jersey: Lawrence Erlbaum.

Elster AB, Lamb ME. (org.) (1986). Adolescent fatherhood. Hillsdale,NewJersey: Lawrence Erlbaum.

Fagot BI, Pears KC, Capaldi DM, Crosby L, Leve CS. (^1998). Becoming an adolescent father: Precursors and parenting. Dev. Psychol., 34 (6), 1209-1219.

Fonseca JL (1997). Patennidade adolescente: Uma proposta de intervenção. [Dissertação de Mestrado - PUCSP].

Fonseca JLCL. (1998). Paternidade adolescente: Da investigação à intervenção. Em M. Arilha SGU. Ridenti, B. Medrado (org.), Homens e masculinidades: Outras palavras (pp. 185214). São Paulo: Editora 34.

Furstenberg FF. (1980). Burdens and benefits: The impact of early childbearing on the family. Journal of Social Issues, 36(1), 64-87.

Harris JLJ. (1998). Urban African American adolescent parents: Their perceptions of Sex, love, intimacy, pregnancy and parenting. Adolescence, 33(132), 833-844.

Heath DT., McKenry PC. (1993). Adult family life of men who fathered as adolescents. Families in society, 74(1), 36-48.

Hendricks LE. (1980). Unwed adolescent fathers: Problems they face and their sources of social support. Adolescence, XV(60), 861-869.

Hendricks LE. (1988). Outreach with teenage fathers: A preliminary report on three ethnic groups. Adolescence, XXIII (91), 711-720.

Hendricks LE, Montgomery T (1983). A limited population of unmarried adolescent fathers: A preliminary report of their views on fatherhood and the relationship with the mothers of their children.Adolescence, XVIII (69), 201-210. 
Jorgensen SR. (1993). Adolescent pregnancy and parenting. Em T P Gullotta GR. Adams, R Montmayor (orgs.), Adolescent sexuality (pp. 103-140). Newbury Park: Sage.

Kiselica MS, Pfaller J (1993). Helping teenage parents: The independent and collaborative roles of counselor educators and school counselors. Jounnal of Counseling and Development, 72(1), 42-48.

Knobel M (1981). A síndrome da adolescência normal. Em A. Aberastury, M. Knobel (orgs.), Adolescência normal: Um enfoque psicanalítico (pp. 24-62), 10a ed. Porto Alegre: Artes Médicas.

Krob AR (1999). A transição para a paternidade e a interação pai-bebê. [Dissertação de Mestrado UFRGS].

Lamb ME, ElsterAB (1985). Adolescent motherinfant - father relationships. Dev Psychol, 21(5), 768-773.

Lamb ME, Elster AB (1986). Parental behavior of adolescent mothers and fathers. Em Adolescent fatherhood (pp. 88-106). Hillsdale, New Jersey: Lawrence Erlbaum.

Levandowski DC, Piccinini CA (2002). A interação pai-bebê entre pais adolescentes e adultos. Psic. Reflex. Crit., 15(2), p.413-424.

Marsiglio W (1986). Teenage fatherhood: High school completion and educational attainment. Em AB Elster, ME Lamb (org.), Adolescent fatherhood (pp. 67-86). Hillsdale, New Jersey: Lawrence Erlbaum.

Marsiglio W, Cohan M (1997). Young fathers and child development. Em M. E. Lamb (org.), The role of the father in child development (pp. 227-244), $3^{\text {a }}$ ed. New York, NY, US: John Wiley, Sons.

Martini TD (1999). A transição para a paternidade: Expectativas, sentimentos e síndrome de couvade dos futuros pais ao longo da gestação. [Dissertação de Mestrado - UFRGS].

Montmayor R (1986). Boys as Fathers: Coping with the dilemmas of adolescence. Em AB Elster, ME Lamb (org.), Adolescent fatherhood (pp. 01-18). Hillsdale, New Jersey: Lawrence Erlbaum.

McAnanney ER, Lawrence RA, Aten MJ, Iker HP (1984). Adolescent mother and their infants. Pediatrics, 73(3), 358-362.

Nakashima II, Camp BW (1984). Father of infant bonn to adolescent mothers: A study of paternal characteristics. American Journal of Disease on Children,138, 452-454.

Nock SL (1998). The consequences of premarital fatherhood. American Sociological Review, 63(2), 250-263.
Nunes CEG (1998). Adolescência e paternidade: Um duelo de papéis sociais. Psico, 29(1), 125138.

Outeiral JO (1994). Adolescer: Estudos sobre adolescência. Porto Alegre: Artes Médicas.

Parke R (1996). Fatherhood. London: Harvard University Press.

Parke RD, Power TG, Fisher T (1980). The adolescent father's impact on the mother and child. Journal of Social Issues, 36(1), 88-106.

Piaget J, Inhelder B (1976). Da lógica da criança à lógica do adolescente: Ensaio sobre a construção das estruturas operatórias formais. São Paulo: Pioneira.

Ramires VR (1997). O exercício da paternidade hoje. Rio de Janeiro: Rosa dos Tempos.

Redmond MA (1985). Attitudes of adolescent males toward pregnancy and fatherhood. Family Relations Journal of Apply Family and Child Studies, 34(3), 337-342.

Reis JS, Herz EJ (1987). Correlates of adolescent parenting. Adolescence, XXII (87), 599-609.

Robinson BE (1988). Teenage pregnancy from the father's perspective. Am. J. Orthopsychiatry, 58(1), 46-51.

Robinson BE, Barret RL (1987). Self-concept and anxiety of adolescent and adult fathers. Adolescence, XXII (87), 611-616.

Robinson RB, Frank DI (1994). The relation between self-esteem, sexual activity, and pregnancy. Adolescence, 29(113), 27-35.

Russell CS (1980). Unescheduled parenthood: Transition to 'parent' for the teenager. Journal of Social Issues, 36(1), 45-63.

Sadler LS, Catrone C (1983). The adolescent parent: A dual developmental crisis. Journal of Adolescent Health Care, 4(1),100-105.

Soares I (1999). Gravidez precoce: Gestações jovens estão sem controle. Jornal Zero Hora, 21 de novembro de 1999, Seção Geral, p. 47-49.

Steinberg L (1985). Adolescence. New York: Alfred Knopf.

Stouthamer-Loeber M, Wei EH (1998). The precursors of young fatherhood and its effect on delinquency of teenage males. J. Adolesc. Health, 22(1), 56-65.

Teti DM, Lamb ME (1986). Sex-role learning and adolescent fatherhood. Em A. B. Elster, M. E. Lamb (org.), Adolescent fatherhood (pp. 1930). Hillsdale, New Jersey: Lawrence Erlbaum.

Trindade E, Bruns MAT. (1998). Pai adolescente: Quem é ele? Rev. Bras. Sex. Hum., 9(1), 2328.

Trindade E, Bruns MA. de T (1999). Adolescentes e paternidade: Um enfoque fenomenológico. Ribeirão Preto: Holos. 
Westney OE, Cole OJ, Munford TL (1986). Adolescent unwed prospective fathers: Readiness for fatherhood and behaviors toward the mother and the expected infant. Adolescence, XXI (84), 901911.

Westney OE, Cole OJ, Munford TL (1988). The effects of prenatal education intervention on unwed prospective adolescent fathers. Journal of Adolescent Health Care, 9, 214-218.
Young M (1988). Parenting during midadolescence: A review of developmental theories and parenting behaviors. J. Matern. Child Nurs., 17(1), 01 - 12.

Recebido em 07/10/2003 Aprovado em 15/12/2003 